NASA Contractor Report 182303

\title{
Turbofan Engine Control System Design Using the LQG/LTR Methodology
}

(NASA-CR-182303) TORBOFAN ENGINE CONTEOL SYSTEM DESIGN USING THE LQG/LTE METHODCLOGY

Final Report (Sverdrup Technology) 24 p

N89-26004

$\begin{array}{lll}\text { CSCL } 21 E & & \text { Unclas } \\ & \text { G3/07 } & 0219603\end{array}$

Sanjay Garg

Sverdrup Technology, Inc.

NASA Lewis Research Center Group

Cleveland, Ohio

June 1989

Prepared for

Lewis Research Center

Under Contract NAS3-25266

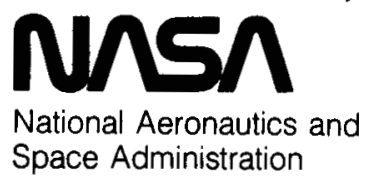


Turbofan Engine Control System Design Using the LQG/LTR Methodology

\author{
Sanjay Garg 1 \\ Sverdrup Technology, Inc. \\ NASA Lewis Research Center Group \\ Cleveland, Ohio 44135
}

\begin{abstract}
Application of the Linear-Quadratic-Gaussian with Loop-Transfer-Recovery methodology to design of a control system for a simplified turbofan engine model is considered. The importance of properly scaling the plant to achieve the desired Target-Feedback-Loop is emphasized. The steps involved in the application of the methodology are discussed via an example, and evaluation results are presented for a reduced-order compensator. The effect of scaling the plant on the stability robustness evaluation of the closed-loop system is studied in detail.
\end{abstract}

${ }^{1}$ Controls Engineer, Member AIAA. 


\section{Nomenclature}

$\mathrm{D}, \mathrm{D}^{*} \quad=$ diagonal scaling matrices for calculating $\mu$

$\mathrm{E}[] \quad=$. Expected value of [.]

$\mathrm{G}(\mathrm{s}) \quad=$ plant transfer function matrix

I $\quad=$ identity matrix

$\mathrm{K}(\mathrm{s}) \quad=$ compensator transfer function matrix

$\mathrm{K}_{\mathrm{F}}, \mathrm{K}_{\mathrm{C}} \quad=$ filter and regulator gains

$\mathrm{M}(\mathrm{s}) \quad=$ transfer function matrix for stability robustness evaluation

$\mathrm{S}_{\mathrm{u}}, \mathrm{S}_{\mathrm{y}} \quad=$ diagonal matrices for scaling plant inputs and outputs

$\mathrm{T}_{\mathrm{O}}(\mathrm{s}) \quad=$ loop transfer function matrix

$\mathrm{q}, \rho, \nu=$ parameters used in LQG/LTR design

$\mathrm{s} \quad=$ laplace variable

$\Gamma \quad=$ process noise distribution matrix

$\mu \quad=$ stability robustness measure

$\sigma_{\mathrm{i}} \quad=$ ith singular value

$\underline{\sigma}, \bar{\sigma} \quad=$ minimum and maximum singular value

$\omega \quad=$ frequency, $\mathrm{rads} / \mathrm{sec}$

\section{Subscripts}

\begin{tabular}{|c|c|}
\hline c & $\equiv$ commanded value \\
\hline $\mathrm{cp}$ & $\equiv$ implementation compensator \\
\hline $\mathrm{p}$ & $\equiv$ plant \\
\hline $\mathrm{p}_{\mathrm{s}}$ & $\equiv$ scaled plant \\
\hline $\mathrm{r}$ & $\equiv$ reduced-order \\
\hline & $\equiv$ scaled value \\
\hline
\end{tabular}




\section{Introduction}

The Linear-Quadratic-Gaussian with Loop-Transfer-Recovery (LQG/LTR) methodology provides an integrated frequency-domain and state-space approach for design of multi-input multi-output (MIMO) control systems. Since the development of the methodology by Stein and Athans [1,2], various applications of the methodology to aerospace systems have been considered, see for example Refs. $[3,4]$. The advantages of the methodology lie in its ability to directly address design issues such as stability robustness and the trade-off between performance and allowable control power. However, as discussed in Ref. [4], blind application of the methodology can result in totally unacceptable compensator designs. So it becomes important that the control system designer exercise certain precautions in the application procedure.

One of the important steps in the application of the LQG/LTR methodology is determining reasonable scaling parameters for the control and output variables. The main objective of this paper is to point out how the choice of scaling parameters impacts the selection of the Target-Feedback-Loop (TFL) which is the starting point of the methodology. Another objective is to go through each design step in detail via a simple, yet insightful, example study so that the practicing engineer will have a ready reference available to assist in more complicated applications.

In the following, the turbofan engine model is discussed and the design specifications are stated. The effect of scaling in the selection of the Target-Feedback-Loop is then presented and a full-order compensator is obtained using the LQG/LTR procedure. A reduced-order compensator is then obtained using a frequency-weighted, internally-balanced realization approach, and the closed-loop system performance, with this low-order compensator, is evaluated. Detailed stability robustness evaluation results are presented to demonstrate the effect of scaling on the stability margins "guaranteed" by the LQG/LTR procedure. 


\section{Engine Model}

The engine model to be considered for the control system design is a simplified linear model of a turbofan engine for a modern fighter aircraft. The engine model has the following state-space form [5] :

$$
\dot{\bar{x}}_{p}=A_{p} \bar{x}_{p}+B_{p} \bar{u}_{p} ; \bar{y}_{p}=C_{p} \bar{x}_{p}
$$

where the state vector is

$$
\overline{\mathrm{x}}_{\mathrm{p}}=\left[\mathrm{N} 1, \mathrm{~N} 2, \mathrm{TM} 45, \mathrm{TM} 3, \mathrm{TM} 5, \mathrm{TM} 6, \xi_{\mathrm{EPR}}\right]^{\mathrm{T}}
$$

with

$\mathrm{N} 1=$ fan speed $(\mathrm{rpm})$

$\mathrm{N} 2=$ low pressure compressor speed $(\mathrm{rpm})$

$\mathrm{TM} 45$ = burner metal temp. $\left({ }^{\circ} \mathrm{R}\right)$

$\mathrm{TM} 3=$ high compressor metal temp. $\left({ }^{\mathrm{O}} \mathrm{R}\right)$

TM5 = turbine inlet metal temp. $\left({ }^{0} \mathrm{R}\right)$

TM6 =high pressure turbine metal temp. $\left({ }^{0} \mathrm{R}\right)$

$\xi_{\mathrm{EPR}}=$ state associated with pressure sensor.

The control input vector is

$$
\overline{\mathrm{u}}_{\mathrm{p}}=[\mathrm{WF}, \mathrm{AJJ}]^{\mathrm{T}}
$$

with

$$
\mathrm{WF}=\text { main burner fuel flow }(1000 \# / \mathrm{hr})
$$

$\mathrm{AJ}=$ nozzle exit area $\left(\mathrm{in}^{2}\right)$,

and the outputs to be sensed and controlled are

$$
\overline{\mathrm{y}}_{\mathrm{p}}=[\mathrm{N} 1, \mathrm{EPR}]^{\mathrm{T}}
$$

with $\mathrm{N} 1$ as before and

$\mathrm{EPR}=$ sensed engine pressure ratio.

The numerical values for the system matrices $\mathrm{A}_{\mathrm{p}}, \mathrm{B}_{\mathrm{p}}$, and $\mathrm{C}_{\mathrm{p}}$ are listed in the Appendix.

The design specifications for the feedback control system were chosen as follows: 
(a) Track $\mathrm{N} 1$ and $\mathrm{EPR}$ commands $\left(\mathrm{N}_{\mathrm{c}}\right.$ and $\mathrm{EPR}_{\mathrm{c}}$ respectively) in a decoupled manner and with zero steady-state error for step commands. Based on performance requirements, stability robustness to unmodelled dynamics such as actuators and sensors, and open-loop analyses of control effectiveness, the desired control bandwidths were chosen as $10 \mathrm{rads} / \mathrm{sec}$ for the $\mathrm{N} 1$ loop and $20 \mathrm{rads} / \mathrm{sec}$ for the EPR loop.

(b) Maintain "adequate" stability margins in all control loops to guarantee stability in the presence of unmodelled dynamics and variation in model parameters.

(c) Avoid "excessive" control input commands and rates to prevent non-linearities (and instabilities) due to control input command and/or rate limiting.

\section{LQG/LTR Compensator Design}

In this section, an LQG/LTR compensator will be designed for the engine model discussed above such that the closed-loop system meets the design specifications. The steps involved in the LQG/LTR design procedure will be discussed by way of this example.

Since the engine model has no integrators and a zero steady-state error for step commands is desired, integral control action (see Ref. [6]) is provided by appending two integrators to the plant - one in each control channel. The augmented plant has the form :

$$
\dot{\overline{\mathrm{x}}}=\mathrm{A} \overline{\mathrm{x}}+\mathrm{B} \overline{\mathrm{u}} ; \overline{\mathrm{y}}=\mathrm{C} \overline{\mathrm{x}}
$$

where $\overline{\mathrm{x}}=\left[\mathrm{x}_{\mathrm{p}}^{\mathrm{T}}, \overline{\mathrm{u}}_{\mathrm{p}}^{\mathrm{T}}\right]^{\mathrm{T}}$ with $\overline{\mathrm{x}}_{\mathrm{p}}$ and $\overline{\mathrm{u}}_{\mathrm{p}}$ as defined before, and $\overline{\mathrm{y}} \equiv \overline{\mathrm{y}}_{\mathrm{p}}$. The system matrices $\mathrm{A}$, $\mathrm{B}$ and $\mathrm{C}$ are given by :

$$
\mathrm{A}=\left[\begin{array}{cc}
\mathrm{A}_{\mathrm{p}} & \mathrm{B}_{\mathrm{p}} \\
0 & 0
\end{array}\right] ; \mathrm{B}=\left[\begin{array}{l}
0 \\
\mathrm{I}
\end{array}\right] ; \mathrm{C}=\left[\mathrm{C}_{\mathrm{p}} 0\right]
$$

The LQG/LTR procedure is based on solving for the optimal compensator that minimizes the performance index

$$
J_{p}=E\left\{\lim _{T \rightarrow \infty} \frac{1}{T} \int_{o}^{T}\left[\left(\bar{z}^{T} \bar{z}+q \bar{y}^{T} V \bar{y}\right)+\rho \bar{u}^{T}\right] d t\right\}
$$


for a system of the form

$$
\begin{gathered}
\dot{\bar{x}}=A \bar{x}+B \bar{u}+\Gamma \bar{\xi} \\
\bar{y}=C \bar{x}+\nu \bar{l} \bar{\eta} \quad ; \quad \bar{z}=H \bar{x}
\end{gathered}
$$

where $\bar{\xi}$ and $\bar{\eta}$ are zero-mean Gaussian white-noise processes with identity intensity, $\overline{\mathrm{y}}$ are the measurements available as compensator inputs, and $\bar{z}$ are the controlled plant outputs. $\mathrm{V}$ is any positive definite symmetric weighting matrix, and $\nu, \mathrm{q}, \rho$ and the process noise distribution matrix $\Gamma$ are the design parameters that are used in the LQG/LTR procedure to synthesize a compensator that would meet the desired specifications. The procedure consists of first designing the Kalman filter such that the filter loop satisfies the performance and stability robustness requirements, and then recovering this loop asymptotically by tuning the regulator. The Kalman filter gains $\left(\mathrm{K}_{\mathrm{F}}\right)$ and the regulator gains $\left(\mathrm{K}_{\mathrm{C}}\right)$ are obtained by solving the appropriate algebraic Riccati equations [6]. Note here that the numerical value of $\mathrm{J}_{p}$ and the process noise matrix $\Gamma$ have no physical significance. The Kalman filter is not actually being designed for state estimation, rather the formulation in (4) is used strictly to exploit the known properties of the quadratic optimal control solution. The block diagram for the LQG compensator design is shown in Fig. 1. In Fig. $1, G_{p}(s)$ is the transfer matrix for the augmented plant given by $G_{p}(s)=$ $\mathrm{C}_{\mathrm{p}}\left(\mathrm{sI}-\mathrm{A}_{\mathrm{p}}\right)^{-1} \mathrm{~B}_{\mathrm{p}}, \mathrm{K}(\mathrm{s})$ represents the transfer matrix of the compensator, and $\mathrm{S}_{\mathrm{u}}$ and $\mathrm{S}_{\mathrm{y}}$ are scaling matrices which will be discussed in a later section. For the engine control problem being considered here, the controlled variables are the same as the measurements, i.e. $\mathrm{H}=\mathrm{C}$, and the matrices $\mathrm{A}, \mathrm{B}$ and $\mathrm{C}$ are as defined in (3).

\section{Target Feedback Loop Specification}

The Kalman filter loop transfer matrix $\left(\mathrm{G}_{\mathrm{KF}}\right)$ is given by

$$
\mathrm{G}_{\mathrm{KF}}(\mathrm{s})=\mathrm{C}(\mathrm{sI}-\mathrm{A})^{-1} \mathrm{~K}_{\mathrm{F}}
$$

When $\underline{\sigma}\left[\mathrm{G}_{\mathrm{KF}}\right]>1$, the Kalman equality can be used to show that

$$
\sigma_{\mathrm{i}}\left[\mathrm{G}_{\mathrm{KF}}(\mathrm{s})\right] \cong \sigma_{\mathrm{i}}\left[\mathrm{G}_{\mathrm{FOL}}(\mathrm{s})\right]
$$


where

$$
\mathrm{G}_{\mathrm{FOL}}(\mathrm{s})=\left(\frac{1}{\sqrt{\nu}}\right) \mathrm{C}(\mathrm{sI}-\mathrm{A})^{-1} \Gamma
$$

Here, $\sigma_{\mathrm{i}}[\cdot]$ denotes the $\mathrm{i}^{\text {th }}$ singular value of $[\cdot]$, defined as

$$
\sigma_{\mathrm{i}}[\mathrm{F}]=\sqrt{\left.\lambda_{\mathrm{i}} \mathrm{F}^{*} \mathrm{~F}\right]}
$$

where $\lambda$ denotes eigenvalue and superscript ${ }^{*}$ denotes complex conjugate transpose, and $\bar{\sigma}$ and $\underline{\sigma}$ are the maximum and minimum singular values, respectively. TheKalman filter loop is to meet the design specifications, then $\Gamma$ and $\nu$ shall be selected in such a way that the maximum and minimum singular values of $\mathrm{G}_{\mathrm{FOL}}$ meet the performance and stability robustness specifications. $\mathrm{G}_{\mathrm{FOL}}$ is hence referred to as the Target Feedback Loop.

From the design specifications stated in the previous section, the requirement on $\mathrm{G}_{\mathrm{FOL}}(\mathrm{s})$ is

$$
\mathrm{G}_{\mathrm{FOL}}(\mathrm{s}) \cong \frac{1}{\mathrm{~s}} \cdot\left[\begin{array}{rr}
10 & 0 \\
0 & 20
\end{array}\right]
$$

i.e. bandwidth of $10 \mathrm{rads} / \mathrm{sec}$ for the N1 loop and $20 \mathrm{rads} / \mathrm{sec}$ for the EPR loop, $\mathrm{k} / \mathrm{s}$ like behavior at loop cross-over for stability robustness, and large low-frequency gain for accurate tracking of commands. This translates into the requirement that $\bar{\sigma}\left[\mathrm{G}_{\mathrm{FOL}}(\mathrm{j} \omega)\right] \cong$ $\frac{20}{\mathrm{j} \omega}$ and $\underline{\sigma}\left[\mathrm{G}_{\mathrm{FOL}}(\mathrm{j} \omega)\right] \cong \frac{10}{\mathrm{j} \omega}$.

In Ref. [2], it is shown that if $\Gamma$ is partitioned as

$$
\Gamma=\left[\begin{array}{l}
\Gamma_{H} \\
\Gamma_{L}
\end{array}\right]
$$

where the partitioning in (10) is consistent with that in (3), then letting

$$
\Gamma_{\mathrm{H}}=\mathrm{C}_{\mathrm{p}}^{\mathrm{T}}\left(\mathrm{C}_{\mathrm{p}} \mathrm{C}_{\mathrm{p}}^{\mathrm{T}}\right)^{-1} \text { and } \Gamma_{\mathrm{L}}=-\left(\mathrm{C}_{\mathrm{p}} \mathrm{A}_{\mathrm{p}}^{-1} \mathrm{~B}_{\mathrm{p}}\right)^{-1}
$$

will result in a Target Feedback Loop such that $\sigma_{\mathrm{i}}\left[\mathrm{G}_{\mathrm{FOL}}(\mathrm{j} \omega)\right] \approx \frac{1}{\omega}$. I at very high and very low frequencies i.e. in the limits $\omega \rightarrow \infty$ and $\omega \rightarrow 0$. With the above choice of $\Gamma, \nu$ is then selected to adjust the loop cross-over frequency to the desired specification. If different bandwidths are desired for the various loops, as is the case in the present example, then the above result can be extended to show that choosing $\Gamma_{\mathrm{H}}$ and $\Gamma_{\mathrm{L}}$ such that

$$
\Gamma_{\mathrm{H}}=\mathrm{C}_{\mathrm{p}}^{\mathrm{T}}\left(\mathrm{C}_{\mathrm{p}} \mathrm{C}_{\mathrm{p}}^{\mathrm{T}}\right)^{-1} \mathrm{G}_{\mathrm{BW}} \text { and } \Gamma_{\mathrm{L}}=-\left(\mathrm{C}_{\mathrm{p}} \mathrm{A}_{\mathrm{p}}^{-1} \mathrm{~B}_{\mathrm{p}}\right)^{-1} \mathrm{G}_{\mathrm{BW}}
$$


where $\mathrm{G}_{\mathrm{BW}}$ is a diagonal matrix of desired loop bandwidths, will result in a Target Feedback Loop such that $\sigma_{\mathrm{i}}\left[\mathrm{G}_{\mathrm{FOL}}(\mathrm{j} \omega)\right]=\frac{1}{\mathrm{~s}} \cdot \mathrm{G}_{\mathrm{BW}}$ in the limits $\omega \rightarrow \infty$ and $\omega \rightarrow 0$. Thus the choice of $\Gamma$ as in (10) and (12) will tend to meet the design specifications of the form (9) in the high frequency and the low frequency regions.

The application of the above procedure for selecting $\Gamma$, with $G_{B W}=\left[\begin{array}{rr}10 & 0 \\ 0 & 20\end{array}\right]$ for the engine model, resulted in the singular values of $\mathrm{G}_{\mathrm{FOL}}(\mathrm{s})$ as shown in Fig. 2. From Fig. 2 it is clear that this choice of $\Gamma$ results in a target loop which does not satisfy the design requirements in the region of desired cross-over. (Although it is not apparent from Fig.2, the requirement (9) is satisfied in the two limits $\omega \rightarrow 0$ and $\omega \rightarrow \infty$ ). Applying the LQG/LTR procedure with the design specifications as implied by this target loop will result in a totally unacceptable compensator design. Also, the large spread in the maximum and minimum singular values in Fig.2 indicates that adjusting $\nu$ will not be of any help in getting the desirable loop-shapes since $\frac{1}{\sqrt{\nu}}$ (in (8)) is simply a gain factor which raises or lowers the singular value plots.

\section{Scaling Effects}

Since the procedure for selecting $\Gamma$ only guarantees the loop shape in the limits $\omega \rightarrow 0$ and $\omega \rightarrow \infty$, the target loop will not reflect the design specifications if there is a large spread in the open-loop plant singular values $\left(\sigma_{\mathrm{i}}\left[\mathrm{G}_{\mathrm{p}}(\mathrm{j} \omega)\right]\right)$ in the region of desired loop bandwidth. Such is the case for the engine model being considered here as seen from $\sigma_{\mathbf{i}}\left[\mathrm{G}_{\mathrm{p}}(\mathrm{j} \omega)\right]$ plotted in Fig. 3. The reason for this spread in the open-loop singular values is the physical units being used for the system input/output description. For instance, the nominal value for the fan speed is $\mathrm{N}_{0}=9637 \mathrm{rpm}$ whereas the nominal value for engine pressure ratio is $\mathrm{EPR}=$ 3.08. Therefore, a unity change in the value of $\mathrm{N} 1$ will be insignificant, whereas a unity change in EPR will be considered a large perturbation. Thus, prior to using the LQG/LTR procedure, it is important that the plant inputs and outputs be normalized (scaled) by a proper choice of values. For the example being considered here, approximate nominal 
values were used to scale the plant inputs and outputs. The scaling is of the form

$$
\bar{u}_{p_{s}}=S_{u} \bar{u}_{p} \quad ; \quad \bar{y}_{p_{s}}=S_{y} \bar{y}_{p}
$$

and the scaled system is given by

$$
\dot{\bar{x}}_{\mathrm{p}}=\mathrm{A}_{\mathrm{p}} \overline{\mathrm{x}}_{\mathrm{p}}+\mathrm{B}_{\mathrm{p}_{\mathrm{s}}} \overline{\mathrm{u}}_{\mathrm{s}} ; \overline{\mathrm{y}}_{\mathrm{p}_{\mathrm{s}}}=\mathrm{C}_{\mathrm{p}_{\mathrm{s}}} \overline{\mathrm{x}}_{\mathrm{p}}
$$

where $\mathrm{B}_{\mathrm{p}_{s}}=\mathrm{B}_{\mathrm{p}} \mathrm{S}_{\mathrm{u}}^{-1}$ and $\mathrm{C}_{\mathrm{p}_{\mathrm{s}}}=\mathrm{S}_{\mathrm{y}} \mathrm{C}_{\mathrm{p}}$. The numerical values of the scaling matrices $\left(\mathrm{S}_{\mathrm{u}}\right.$ and $\mathrm{S}_{\mathrm{y}}$ ) used for this study are listed in the Appendix.

The singular values of the scaled plant $\left(\sigma_{\mathrm{i}}\left[\mathrm{G}_{\mathrm{p}_{\mathrm{s}}}(\mathrm{j} \omega)\right]\right.$ where $\left.\mathrm{G}_{\mathrm{p}_{\mathrm{s}}}(\mathrm{j} \omega)=\mathrm{C}_{\mathrm{p}_{\mathrm{s}}}(\mathrm{j} \omega \mathrm{I}-\mathrm{A})^{-1} \mathrm{~B}_{\mathrm{p}_{\mathrm{s}}}\right)$ are also shown in Fig. 3. Note that the scaling has the effect of bringing the maximum and minimum singular values close together in the region of the desired bandwidth. The singular values of $\mathrm{G}_{\mathrm{FOL}}(\mathrm{j} \omega)$ with $\nu=1$ and $\Gamma$ obtained by applying the procedure discussed earlier are shown in Fig.4. The Target Feedback Loop in Fig. 4 has the desired shape as well as the desired bandwidth. The rest of the design steps are then performed with the augmented plant matrices, A, B and C, obtained by replacing the plant matrices $A_{p}, B_{p}$ and $C_{p}$, by the scaled plant matrices, $A_{p_{s}}, B_{p_{s}}$ and $C_{p_{s}}$, in (3).

\section{Kalman Filter Design}

After satisfactory values for $\Gamma$ and $\nu$ have been determined, the filter gains are obtained by solving the following algebraic Riccati equation

$$
\mathrm{A} \Sigma+\Sigma \mathrm{A}^{\mathrm{T}}+\Gamma \Gamma^{\mathrm{T}}-\left(\frac{1}{\nu}\right) \Sigma \mathrm{C}^{\mathrm{T}} \mathrm{C} \Sigma=0 ; \mathrm{K}_{\mathrm{F}}=\left(\frac{1}{\nu}\right) \Sigma \mathrm{C}^{\mathrm{T}}
$$

The singular values of the filter loop $\left(\sigma_{\mathrm{i}}\left[\mathrm{G}_{\mathrm{KF}}(\mathrm{j} \omega)\right]\right)$ are then compared with the singular values of the Target Feedback Loop to make sure of a reasonable agreement between the two.

The Kalman Filter designed using (14) with the scaled engine model resulted in the $\sigma_{\mathrm{i}}\left[\mathrm{G}_{\mathrm{KF}}(\mathrm{j} \omega)\right]$ shown in Fig. 5. Comparing Fig. 5 to Fig. 4, we note that the Kalman filter loop shape is just like that of the Target Feedback Loop.

\section{Loop Transfer Recovery}

Having solved for the Kalman filter gains that lead to the desired filter loop-shapes, 
the next step in the LQG/LTR procedure consists of solving for the full state feedback regulator gains, $\mathrm{K}_{\mathrm{C}}$. With $\mathrm{V}$ chosen to be identity and $\rho=1$ for convenience, and for the case where the controlled variables are the same as the measurements, i.e. $\mathrm{H}^{\mathrm{T}} \mathrm{H}$ need not be considered separately in Eqn. (4), the regulator gains are obtained as the solution to the following equation

$$
\mathrm{PA}+\mathrm{A}^{\mathrm{T}} \mathrm{P}+\mathrm{qC}^{\mathrm{T}} \mathrm{C}-\mathrm{PB}^{\mathrm{T}} \mathrm{BP}=0 ; \mathrm{K}_{\mathrm{C}}=\mathrm{B}^{\mathrm{T}} \mathrm{P}
$$

The LQG/LTR compensator transfer function matrix is then given by

$$
\mathrm{K}_{\mathrm{LQG} / \mathrm{LTR}}{ }^{(\mathrm{s})}=\mathrm{K}_{\mathrm{C}}{ }^{[\mathrm{SI}-(\mathrm{A}-\mathrm{BK}} \mathrm{C}^{\left.\left.-\mathrm{K}_{\mathrm{F}} \mathrm{C}\right)\right]^{-1} \mathrm{~K}_{\mathrm{F}}}
$$

and the loop transfer function matrix, with the loop broken at the output is given by

$$
\mathrm{T}_{\mathrm{o}}(\mathrm{s})=\mathrm{G}(\mathrm{s}) \mathrm{K}_{\mathrm{LQG} / \mathrm{LTR}^{(\mathrm{s})}}
$$

where $\mathrm{G}(\mathrm{s})=\mathrm{C}(\mathrm{sI}-\mathrm{A})^{-1} \mathrm{~B}$ is the transfer matrix for the augmented scaled plant.

In the synthesis procedure for the regulator gains, under certain restrictions (see Ref. [1] for details), as $q \rightarrow \infty$ the loop transfer function approaches the Kalman filter loop transfer function, i.e. $\mathrm{T}_{\mathrm{o}}(\mathrm{s}) \rightarrow \mathrm{G}_{\mathrm{KF}}(\mathrm{s})$ pointwise in $\mathrm{s}$. Thus, if the filter loop meets the desired specifications, then asymptotically the LQG/LTR procedure will result in a compensator that will also meet the specifications.

For the engine control problem, the singular values of the loop transfer function matrix $\left(\sigma_{\mathrm{i}}\left[\mathrm{T}_{\mathrm{o}}(\mathrm{j} \omega)\right]\right)$ for $\mathrm{q}=10^{8}$ are compared with the Kalman filter loop singular values in Fig. 5. Clearly, the LQG/LTR compensator loop matches the Kalman filter loop. The compensator corresponding to $\mathrm{q}=10^{8}$ will be considered to be the design LQG/LTR compensator for this example and will be evaluated further. This design compensator will have the guaranteed stability margins of the Linear Quadratic Regulator (see Ref. [7]) at the design plant output since the compensator loop closely matches the Kalman filter loop. The closed-loop system frequency response to command inputs, with the design compensator, is shown in Figs. 6(a) and 6(b). Note that in Figs. 6(a) and 6(b), the command inputs and the responses are in terms of the scaled (normalized) variables $\bar{y}_{\mathrm{S}}$. From these figures we note that the design compensator provides decoupled command 
following with the specified bandwidths.

\section{Compensator Order Reduction and Evaluation}

The LQG/LTR compensator designed in the previous section is of order 9. It is desirable to reduce the order of the compensator in order to simplify its implementation. A numerical analysis of the LQG/LTR compensator showed that it is of minimal order, so direct simplification using a controllability/observability approach was not possible. A frequency-weighted internally-balanced reduction technique [8] was used to reduce the order of the compensator. This approach consists of designing a lower order compensator which approximates the frequency response of the elements of the matrix $K(j \omega) \cdot W(j \omega)$ where $W(j \omega)$ denotes the matrix of frequency dependent weightings and $K(j \omega)$ is the frequency response of the full order compensator. The approximation is constrained to be of the form $\mathrm{K}_{\mathrm{r}}(\mathrm{j} \omega) \cdot \mathrm{W}(\mathrm{j} \omega)$ where $\mathrm{K}_{\mathrm{r}}(\mathrm{j} \omega)$ is the reduced order compensator. The internally-balanced realization algorithm of Ref. [9] has to be appropriately modified in order to obtain the desired form of the approximation. Based on closed-loop system stability considerations, it was postulated by Enns [8] that a reasonable choice for $W(j \omega)$ is $\mathrm{W}=\mathrm{G}(\mathrm{I}+\mathrm{GK})^{-1}$ where $\mathrm{G}(\mathrm{j} \omega)$ is the frequency response for the plant for which the compensator is being designed. A detailed step-by-step algorithm for applying this reduction technique is discussed in Ref. [10].

A visual comparison of the singular values of the full $\left(9^{\text {th }}\right)$ order compensator and a $5^{\text {th }}$ order approximation, obtained using the reduction technique discussed above, showed a perfect match between the singular values of the two compensators. The eigenvalues of the full and the $5^{\text {th }}$ order compensator are listed in Table 1 . From Table 1 we note that the reduction technique preserves the high frequency modes of the full order compensator and lumps the slow modes $\left(\lambda_{1}=-0.284\right.$ to $\left.\lambda_{5}=-5.025\right)$ into a single mode at $\lambda=-4.743$. 
Table 1. Eigenvalues of Full and Reduced-Order Compensators

$$
\begin{aligned}
& \underline{\lambda-\text { Full-Order (9) }} \\
& \underline{\lambda \text {-Reduced-Order (5) }} \\
& -7.64 \mathrm{e}+02 \pm \mathrm{j} 7.61 \mathrm{e}+02 \\
& -9.29 \mathrm{e}+01 \pm \mathrm{j} 9.27 \mathrm{e}+01 \\
& -5.025 \\
& -1.260 \\
& -0.881 \\
& -0.742 \\
& -0.284
\end{aligned}
$$

It is interesting to point out here that initial attempts at obtaining reduced order compensators simply by residualizing the high frequency modes were unsuccessful. The results in Table 1 clearly demonstrate the importance of preserving the high frequency modes. Also, no further reduction in the order of the compensator could be obtained using the above frequency-weighted reduction procedure as $4^{\text {th }}$ and $3^{\text {rd }}$ order approximations resulted in poor approximations in the region of the specified control bandwidth. In the following, closed-loop system evaluation results, with the $5^{\text {th }}$ order compensator, are presented.

The singular values of the loop transfer function $\left(\sigma_{\mathrm{i}}\left[\mathrm{T}_{0}(\mathrm{j} \omega)\right]\right)$ with the $5^{\text {th }}$ order compensator were found to closely match those of the loop with the full order compensator. Therefore, the closed-loop system with the reduced order compensator should also have the desired stability robustness. Lehtomaki et al. [7] have shown that a reliable (but sometimes conservative) measure of stability robustness is the minimum singular value of the return difference matrix evaluated as a function of $j \omega$. Fig. 7 shows the minimum singular value of the return difference matrix, with the reduced order compensator, for the loop broken at the output $\left(\sigma\left[\mathrm{I}+\mathrm{GK}_{\mathrm{r}}(\mathrm{j} \omega)\right]\right)$. The lowest value of the minimum singular value, in the frequency region of interest, is $\approx 0.93$ which is very close to 1 , thus indicating that the closed-loop system stability robustness with respect to unstructured uncertainties occurring at the design plant output will be quite close to the LQR guaranteed stability robustness. The lowest value of the minimum singular value of the return difference matrix at the design plant input $\left(\underline{\sigma}\left[\mathrm{I}+\mathrm{K}_{\mathrm{r}} \mathrm{G}(\mathrm{j} \omega)\right]\right)$ was found to be $\approx 0.84$, implying that the 
closed-loop system will have adequate stability robustness for perturbations at the design plant input also. However, it is important to realize that these excellent stability robustness properties are guaranteed for the loops broken at the points (1) and (2) in the LQG/LTR compensator design block diagram of Fig. 1. The actual control system implementation will be as shown in the block diagram of Fig. 8, wherein the interface between the physical system $\left(G_{p}(s)\right)$ and the control system $\left(K_{p}(s)\right)$ is at the points $\left(1^{\prime}\right)$ and $\left(2^{\prime}\right)$. It is at these points in the loop that we need "good" stability margins.

If the compensator $\mathrm{K}(\mathrm{s})$, from Fig. 1, has the state-space representation

$$
\dot{\bar{x}}_{c}=A_{c} \bar{x}_{c}+B_{c} \bar{e}_{s} ; \bar{u}=C_{c} \bar{x}_{c}
$$

where $\overline{\mathrm{e}}_{\mathrm{S}}=\overline{\mathrm{y}}_{\mathrm{Sc}}-\overline{\mathrm{y}}_{\mathrm{S}}$, then through simple algebraic manipulation it can be shown that the compensator $\mathrm{K}_{\mathrm{p}}(\mathrm{s})$, from Fig. 8, will have the following state-space representation

$$
\dot{\overline{\mathrm{x}}}_{\mathrm{cp}}=\mathrm{A}_{\mathrm{cp}} \overline{\mathrm{x}}_{\mathrm{cp}}+\mathrm{B}_{\mathrm{cp}} \overline{\overline{\mathrm{e}}} ; \overline{\mathrm{u}}_{\mathrm{p}}=\mathrm{C}_{\mathrm{cp}} \overline{\mathrm{x}}_{\mathrm{cp}}
$$

where $\overline{\mathrm{e}}=\overline{\mathrm{y}}_{\mathrm{pc}}-\overline{\mathrm{y}}_{\mathrm{p}}$ and the matrices $\mathrm{A}_{\mathrm{cp}}, \mathrm{B}_{\mathrm{cp}}$ and $\mathrm{C}_{\mathrm{cp}}$ are given by

$$
A_{c p}=\left[\begin{array}{ll}
A_{c} & 0 \\
C_{c} & 0
\end{array}\right] ; \quad B_{c p}=\left[\begin{array}{cc}
B_{c} S_{y} \\
0
\end{array}\right] ; C_{c p}=\left[\begin{array}{ll}
0 & S_{u}^{-1}
\end{array}\right]
$$

With the above form of the compensator, the stability robustness of the closed-loop system was analyzed using the return difference singular values. The minimum return difference singular value at the actual plant output $\left(\underline{\sigma}\left[\mathrm{I}+\mathrm{G}_{\mathrm{p}} \mathrm{K}_{\mathrm{p}}(\mathrm{j} \omega)\right]\right.$, for point $\left(2^{\prime}\right)$ of Fig. 8 ), shown in Fig. 7 , has a lowest value of $\approx 0.01$ which indicates very low stability robustness to unstructured uncertainties occurring at this point in the loop. Recalling that the reduced-order compensator closely approximates the full-order LQG/LTR compensator, it would appear from this analysis that the claim that the LQG/LTR methodology recovers the guaranteed stability robustness properties of the LQR (Linear Quadratic Regulator) is misleading. The stability robustness properties are recovered, but not at the physical interface between the plant and the control system where the effect of the modeling uncertainties will actually occur. The minimum return difference singular value at the actual plant input $\left(\underline{\sigma}\left[\mathrm{I}+\mathrm{K}_{\mathrm{p}} \mathrm{G}_{\mathrm{p}}(\mathrm{j} \omega)\right]\right.$, for point (1') of Fig. 8) had a lowest value 
of $\approx 0.4$ which is also much reduced from that for point (1) of Fig. 1 .

Although the above results indicate that the implementation system (as in Fig. 8) will have much reduced stability robustness with respect to unstructured uncertainties as compared to the design system (as in Fig. 1), it will be shown in the following that as far as stability robustness with respect to structured uncertainties in the form of loop gain or phase variations are concerned, the implementation system will have the same guaranteed multivariable stability margins as obtained for the design system. A nonconservative measure of stability robustness for structured uncertainties, called $\mu$ or the structured singular value, has recently been developed [11,12]. A detailed mathematical discussion of the definition and properties of $\mu$, and the form of structured uncertainties that can be analyzed using $\mu$ can be found in Ref. [11]. For the case of loop gain or phase variations, this stability robustness measure is given by

$$
\mu[\mathrm{M}(\mathrm{j} \omega)]=\min _{\mathrm{D} \in D^{-}}\left[\mathrm{DM}(\mathrm{j} \omega) \mathrm{D}^{-1}\right]
$$

where $\mathrm{M}$ is the return difference matrix at the loop point where the gain or phase variations are being considered (for example, $\mathrm{M}=\mathrm{I}+\mathrm{KG}(\mathrm{j} \omega)$ for point (1) of Fig. 1), and $\mathscr{D}$ is the set of all real diagonal matrices. In Ref. [12] it is shown that if

$$
\mu[\mathrm{M}(\mathrm{j} \omega)] \geq \mu_{\min }, 0<\omega<\infty
$$

for some constant $\mu_{\min } \leq 1$, then the nonconservative guaranteed multivariable gain and phase margins are given by

$$
\begin{aligned}
& \text { Gain Margin : } \quad \mathrm{GM}=\frac{1}{1 \pm \mu_{\min }} \\
& \text { Phase Margin : } \mathrm{PM}= \pm 2 \sin ^{-1}\left(\frac{\mu_{\mathrm{min}}}{2}\right)
\end{aligned}
$$

Denoting the M-matrix at point $(i)$ by $\mathrm{M}_{i}$, and considering the point ( $\left.2^{\prime}\right)$, i.e. the actual plant output, we have

$$
\begin{aligned}
\mathrm{M}_{2^{\prime}} & =\mathrm{I}+\mathrm{G}_{\mathrm{p}} \mathrm{K}_{\mathrm{p}} \\
& =\mathrm{I}+\mathrm{G}_{\mathrm{p}} \mathrm{S}_{\mathrm{u}}^{-1}\left(\frac{1}{\mathrm{~s}} \mathrm{I}\right) \mathrm{KS}_{\mathrm{y}}
\end{aligned}
$$




$$
\begin{aligned}
& =I+S_{y}^{-1} G K S_{y} \\
& =S_{y}^{-1}[I+G K] S_{y} \\
\Rightarrow \quad M_{2^{\prime}}= & S_{y}^{-1} M_{2^{\prime}} S_{y}
\end{aligned}
$$

Since $S_{y} \in \mathscr{D}$, from (21) we have

$$
\mu\left[\mathrm{M}_{2^{\prime}}(\mathrm{j} \omega)\right]=\mu\left[\mathrm{M}_{2}(\mathrm{j} \omega)\right]
$$

which implies that $\mu_{\min _{2}}=\mu_{\min _{2}}$. Hence the guaranteed multivariable gain and phase margins at point (2) will be the same as those at point (2'). Proceeding in a similar manner, it can be shown that the above is true for points (1') and (1) also.

For the special case of gain and phase variations being considered here, the optimal matrix $\mathrm{D}^{*}$ corresponding to the minimum structured singular value $\mu$ in Eqn. (21) can be obtained using a globally convergent algorithm developed by Osborne[13]. This algorithm was applied to the return difference matrices at points (1) and (2) with the reduced order compensator $\mathrm{K}_{\mathrm{r}}$, and resulted in the following values of the optimal diagonal matrices

$$
\mathrm{D}_{1}^{*}=\left[\begin{array}{cc}
0.072 & 0 \\
0 & 1.0
\end{array}\right] \quad ; \quad \mathrm{D}_{2}^{*}=\left[\begin{array}{cc}
0.96 & 0 \\
0 & 1.0
\end{array}\right]
$$

With the above scaling matrices, the structured singular values resulted in $\mu_{\min _{1}}=$ 0.86 and $\mu_{\min _{2}}=0.93$. Using (23), these results imply that the closed loop system will have guaranteed multivariable gain margins of $-5.4 \mathrm{~dB}$ to $17.4 \mathrm{~dB}$ and phase margins of \pm 50.9 deg for variations at the plant input, and gain margins of $-5.7 \mathrm{~dB}$ to $23.1 \mathrm{~dB}$ and phase margins of $\pm 55.4 \mathrm{deg}$ at the plant output. Note that $\mu_{\min _{2}}$ is equal to the lowest value of $\underline{\sigma}\left[\mathrm{I}+\mathrm{GK}_{\mathrm{r}}(\mathrm{j} \omega)\right]$ which is to be expected since $\mathrm{D}_{2}^{*} \approx \mathrm{I}$. However, it was surprising to find that $\mu_{\min _{1}}$ is so close to the lowest value of $\sigma\left[\mathrm{I}+\mathrm{K}_{\mathrm{r}} \mathrm{G}(\mathrm{j} \omega)\right]$ even though $\mathrm{D}_{1}^{*}$ is very different from the identity matrix.

One final note of interest is that, from (24),the optimal diagonal matrices $D^{*}$ for points (2) and (2') are related as follows

$$
\mathrm{D}_{2^{\prime}}^{*}=\mathrm{pD}_{2}^{*} \mathrm{~S}_{\mathrm{y}}^{-1}
$$


where $\mathrm{p}$ is a scalar. So, if the compensator $\mathrm{K}(\mathrm{s})$ in Fig. 1 was such that it exactly recovers the Kalman filter loop, i.e. $\inf (\sigma[\operatorname{I}+\mathrm{GK}(\mathrm{j} \omega)])=1$, then we will get $\mathrm{D}_{2}^{*}=\mathrm{I}$ and hence $\mathrm{D}_{2^{\prime}}^{*}=\mathrm{pS}_{\mathrm{y}}^{-1}$, or in other words the structured singular value scaling matrix for determining nonconservative stability margins will be just the inverse of the diagonal matrix used to scale the plant outputs to do the compensator design. A similar result can be obtained for points (1) and (1').

Using the implementation form of the reduced order compensator, time-histories of the closed-loop system responses as well as control input variations for step command inputs were obtained. Fig. 9 shows the N1 response to step N1 and EPR commands $\left(\mathrm{N}_{\mathrm{c}}=100 \mathrm{rpm}\right.$ and $\mathrm{EPR}_{\mathrm{c}}=0.03$, approximately $1 \%$ of nominal values $)$ while Fig. 10 shows the EPR responses to these commands. From these figures we note that the closed-loop system provides well-damped decoupled command following with fast rise-time and zero steady-state error. Fig. 11 shows the fuel flow required to track the step commands while Fig 12 shows the required nozzle throat area changes. The steady-state control variations are less than $1 \%$ of the corresponding nominal values and so can be considered to be quite reasonable. The initial control rate requirements, however, appear to be very high, especially the fuel flow rate (WF) required for tracking the N1 commands. Although these control rate requirements are within the maximum allowable limits, which are in the order of $15,000 \# / \mathrm{hr} / \mathrm{sec}$ for $\mathrm{W} \dot{\mathrm{F}}$ and $248 \mathrm{in}^{2} / \mathrm{sec}$ for $\mathrm{AJ}$ for the type of engine being considered, further evaluation with the fuel valve and nozzle actuator dynamics included in the closed loop system might be desirable to ascertain that the design compensator does not cause control rate limiting.

\section{Conclusion}

Application of the Linear-Quadratic-Gaussian with Loop-Transfer-Recovery (LQG/LTR) methodology to the design of a control system for a simplified turbofan engine 
model was considered. The importance of properly scaling (normalizing) the plant to achieve the desired Target-Feedback-Loop was demonstrated. The application of the methodology was discussed in detail via the engine example. A $9^{\text {th }}$ order compensator obtained by the application of the methodology was closely approximated by a reduced, $5^{\text {th }}$ order compensator using a frequency-weighted internally-balanced reduction technique. The closed-loop system with this reduced order compensator provides decoupled tracking of command inputs, well-damped and fast rise-time response, and zero steady-state error for step command inputs. Also shown via the example, was the inability of the LQG/LTR procedure to guarantee stability robustness properties with respect to unstructured uncertainties at the physical interface between the plant and the compensator. However, as far as structured uncertainties in the form of loop gain or phase variations are concerned, it was shown that the guaranteed stability margins for simultaneous gain or phase variations at the physical interface between the plant and the compensator are the same as those obtained at the interface between the design plant and the LQG/LTR based compensator.

\section{Appendix}

Engine Model System Matrices

$$
\begin{aligned}
& \mathrm{A}_{\mathrm{p}}=\left[\begin{array}{rrrrrrr}
-3.25 \mathrm{e}+00 & 1.98 \mathrm{e}+00 & 8.03 \mathrm{e}-01 & 1.94 \mathrm{e}-01 & 1.53 \mathrm{e}+00 & 1.65 \mathrm{e}+00 & 0.0 \\
-4.73 \mathrm{e}-01 & -2.88 \mathrm{e}+00 & 1.63 \mathrm{e}+00 & 2.30 \mathrm{e}-01 & 2.27 \mathrm{e}+00 & -1.00 \mathrm{e}+00 & 0.0 \\
4.64 \mathrm{e}-02 & 3.66 \mathrm{e}-02 & -8.99 \mathrm{e}-01 & 7.38 \mathrm{e}-04 & 7.44 \mathrm{e}-03 & 2.48 \mathrm{e}-03 & 0.0 \\
-9.72 \mathrm{e}-04 & -1.32 \mathrm{e}-02 & 5.35 \mathrm{e}-02 & -2.76 \mathrm{e}-01 & 8.16 \mathrm{e}-04 & -4.17 \mathrm{e}-03 & 0.0 \\
-1.54 \mathrm{e}-03 & -4.49 \mathrm{e}-02 & 1.81 \mathrm{e}-01 & 3.14 \mathrm{e}-02 & -1.00 \mathrm{e}+00 & -1.43 \mathrm{e}-02 & 0.0 \\
1.43 \mathrm{e}-02 & 8.82 \mathrm{e}-03 & 1.34 \mathrm{e}-01 & 8.96 \mathrm{e}-03 & 7.01 \mathrm{e}-02 & -7.02 \mathrm{e}-01 & 0.0 \\
1.43 \mathrm{e}-04 & 1.72 \mathrm{e}-05 & 4.91 \mathrm{e}-05 & 1.16 \mathrm{e}-05 & 8.82 \mathrm{e}-05 & 9.24 \mathrm{e}-05 & -1.00 \mathrm{e}+02
\end{array}\right] \\
& \mathrm{B}_{\mathrm{p}}=\left[\begin{array}{cc}
6.58 \mathrm{e}+02 & 2.76 \mathrm{e}+01 \\
7.56 \mathrm{e}+02 & 2.01 \mathrm{e}+01 \\
2.69 \mathrm{e}+00 & -2.68 \mathrm{e}-01 \\
2.71 \mathrm{e}+01 & 4.32 \mathrm{e}-01 \\
9.38 \mathrm{e}+01 & 1.48 \mathrm{e}+00 \\
2.70 \mathrm{e}+01 & 3.13 \mathrm{e}-01 \\
4.17 \mathrm{e}-02 & -7.72 \mathrm{e}-03
\end{array}\right] \\
& \mathrm{C}_{\mathrm{p}}=\left[\begin{array}{ccccccc}
1.0 & 0 & 0 & 0 & 0 & 0 & 0 \\
0 & 0 & 0 & 0 & 0 & 0 & 100.0
\end{array}\right]
\end{aligned}
$$




\section{Scaling Matrices}

The nominal operating values are :

$$
\begin{gathered}
\mathrm{Nl}_{\mathrm{o}}=9637 \mathrm{rpm} ; \mathrm{EPR}_{\mathrm{o}}=3.08 \\
\mathrm{WF}_{\mathrm{o}}=20(1000 \#) / \mathrm{hr} ; \mathrm{AJ}_{\mathrm{o}}=432 \mathrm{in}^{2}
\end{gathered}
$$

Normalizing the inputs and the outputs by the nominal values results in the following scaling matrices

$$
S_{y}=\left[\begin{array}{cc}
0.0001 & 0 \\
0 & 0.33
\end{array}\right] \quad ; \quad S_{u}=\left[\begin{array}{cc}
0.05 & 0 \\
0 & 0.0023
\end{array}\right]
$$

\section{Acknowledgement}

This study was conducted as part of the ongoing research effort in the Advanced Control Technology Branch (ACTB), NASA Lewis Research Center, on Integrated Flight and Propulsion Control (IFPC) design for Short Take-off and Vertical Landing (STOVL) aircraft. Mr. Carl F. Lorenzo, Chief, ACTB, is managing the research effort. The author would also like to thank Prof. David K. Schmidt for insightful discussions regarding the effect of scaling on stability robustness evaluation.

\section{References}

[1] Stein, G., and Athans, M., "The LQG-LTR Procedure for Multivariable Feedback Control Design," Report LIDS-R-1384, Massachusetts Institute of Technology, Cambridge, MA., May 1984.

[2] Athans, M., "A Tutorial on the LQG/LTR Method," LIDS-P-1542, Massachusetts Institute of Technology, Cambridge, MA, March 1986.

[3] Athans, M., Kapassouris, P., Kappos, E., and Spang III, H.A., "Linear-Quadratic Gaussian with Loop-Transfer Recovery Methodology for the F-100 Engine," AIAA Journal of Guidance, Control and Dynamics, Vol. 9, Jan.-Feb. 1986, pp. 45-52.

[4] Ridgley, B.D., Banda, S.S., McQuade, T.E., and Lynch, P.J., "Linear-Quadratic Gaussian with Loop-Transfer Recovery Methodology for an Unmanned Aircraft," AIAA Journal of Guidance Control and Dynamics, Vol. 10, Jan.-Feb. 1987, pp. $82-89$.

[5] Hartmann, G. et al., "Design Methods for Integrated Control Systems - Control Design Workshop," Aug. 1986, Honeywell Systems and Research Center, Minneapolis, MN. 
[6] Kwakernaak, H., and Sivan, R., "Linear Optimal Control Systems," Wiley Interscience, 1972.

[7] Lehtomaki, N.A., Sandell, N.S.,Jr., and Athans, M., "Robustness results in Linear Quadratic Gaussian based Multivariable Control Designs," IEEE Trans. on Automatic Control, Vol. 26, Feb. 1981, pp. 75-92.

[8] Enns, D.F., "Model Reduction for Control System Design," Ph. D. Thesis, Department of Aeronautics and Astronautics, Stanford University, Stanford, CA., June 1984.

[9] Moore, B.C., "Principal Component Analysis in Linear Systems: Controllability, Observability, and Model Reduction," IEEE Trans. on Automatic Control, Vol. AC-26, Feb. 1981.

[10] Bacon, B.J., and Schmidt, D.K., "Mathematics of Equivalent Models for Aircraft Dynamics," Report No. NADC-87146-60, July 1987.

[11] Safonov, M.G., and Doyle, J.C., "Minimizing Conservativeness of Robustness Singular Values," S.G. Tzefestas (ed.), ul Multivariable Control, D. Reidel Publishing Company, Dordrecht, Holland, 1984, pp. 197-207.

[12] Apkarian, P.R., "Structured Stability Robustness Improvement by Eigenspace Assignment Techniques: A Hybrid Methodology," Journal of Guidance, Control and Dynamics, Vol. 12, No. 2, March-April 1989, pp. 162-168.

[13] Osborne, E.E., "On Pre-Conditioning of Matrices," Journal of the Association for Computing Machinery, Vol. 7, 1960, pp. 338-345.

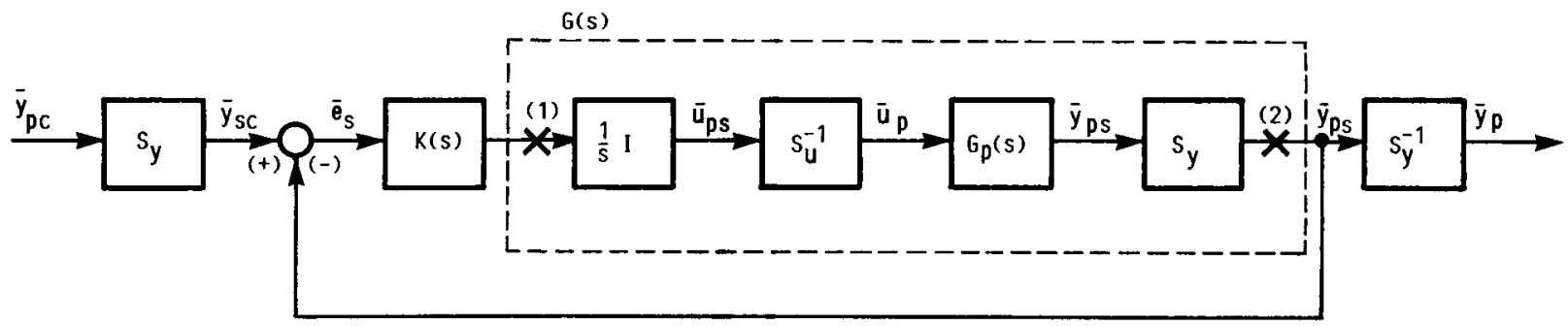

FIGURE 1. - BLOCK DIAGRAM FOR LQG/LTR COMPENSATOR DESIGN. 


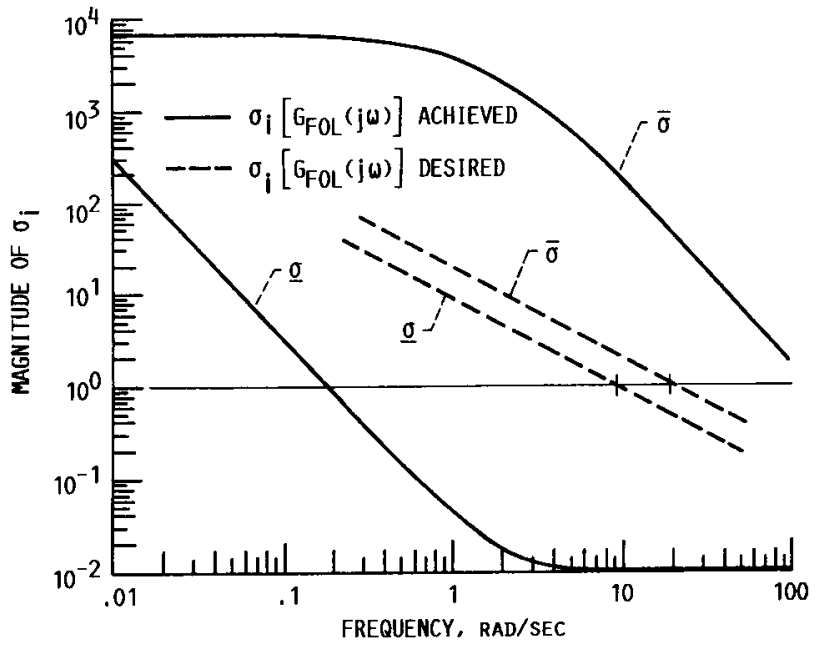

Figure 2. - tARGET LOOP SINGULAR VALUES $\left(\sigma_{i}\left[G_{F O L}(j \omega)\right]\right)$.

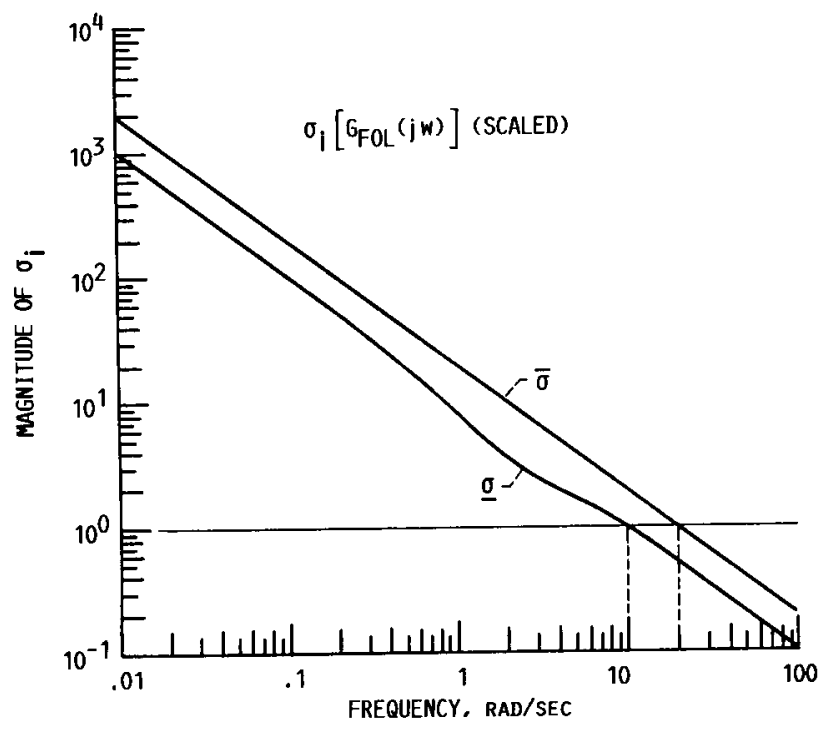

FIGURE 4. - TARGET LOOP SINGULAR VALUES WITH SCALED PLANT.

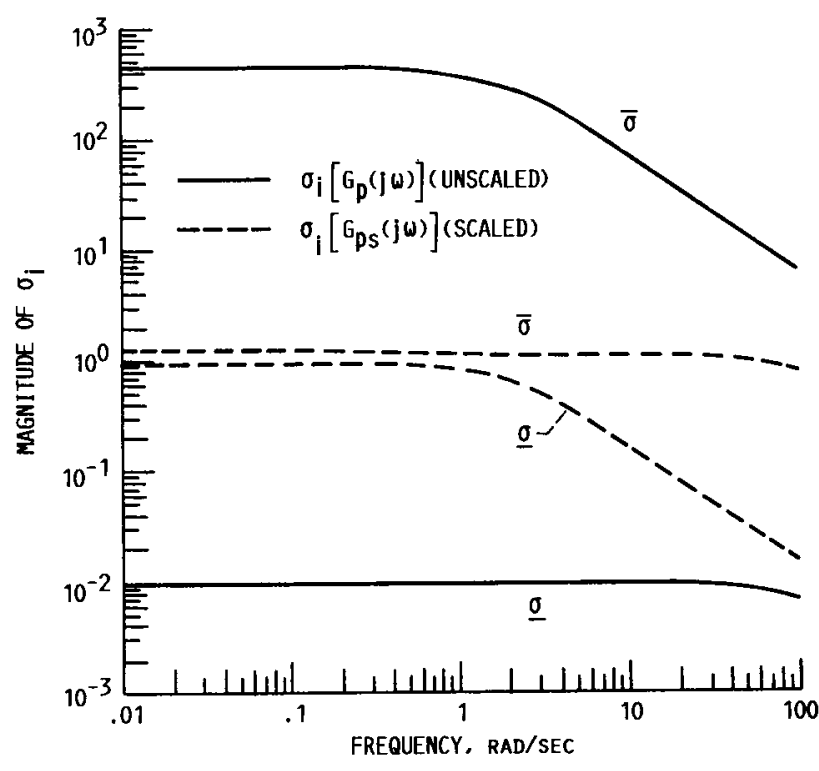

Figure 3. - PLANT Singular VALUES, UNSCALED AND SCALED.

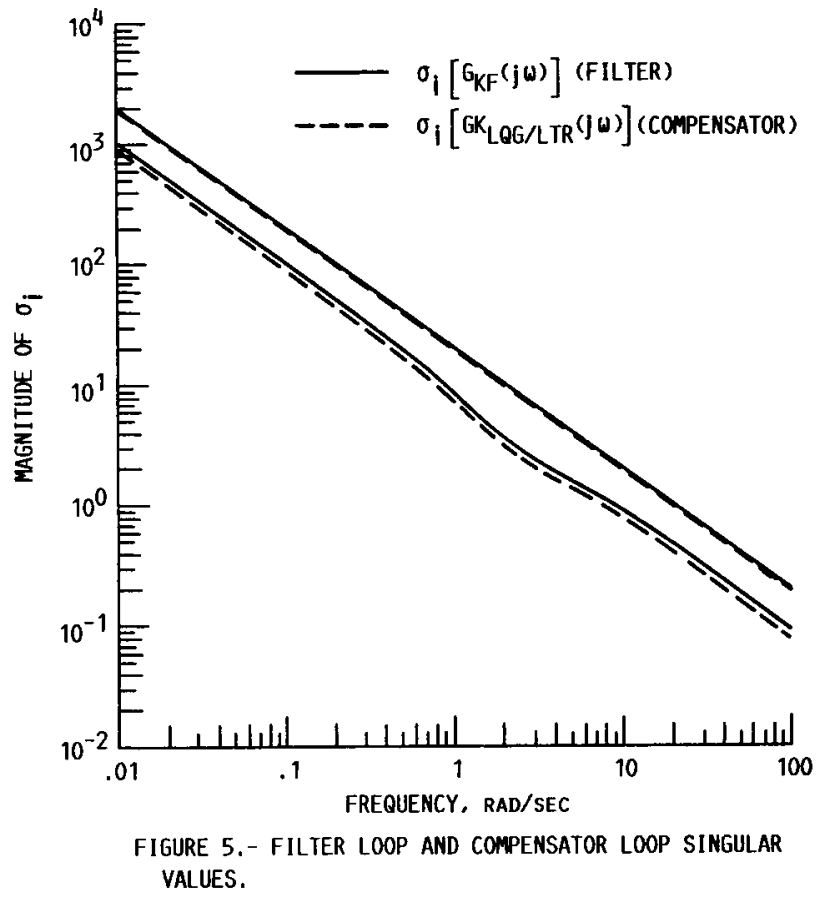



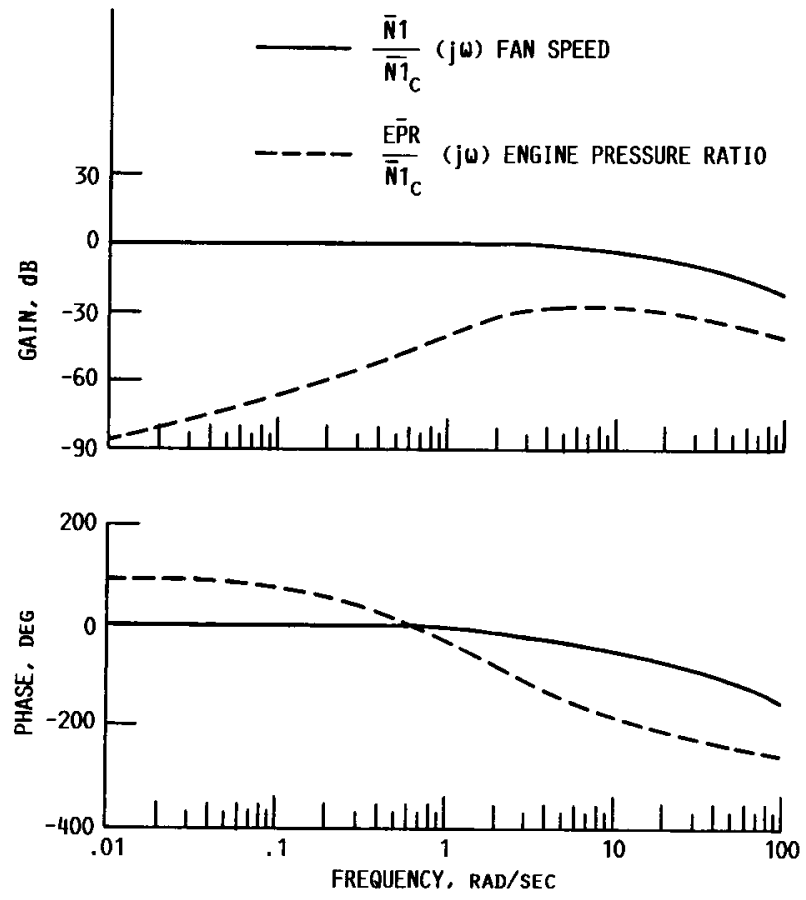

FIGURE 6A. - CLOSED-LOOP SYSTEM FREQUENCY RESPONSE TO FAN SPEED (N1) COMMANDS (SCALED).
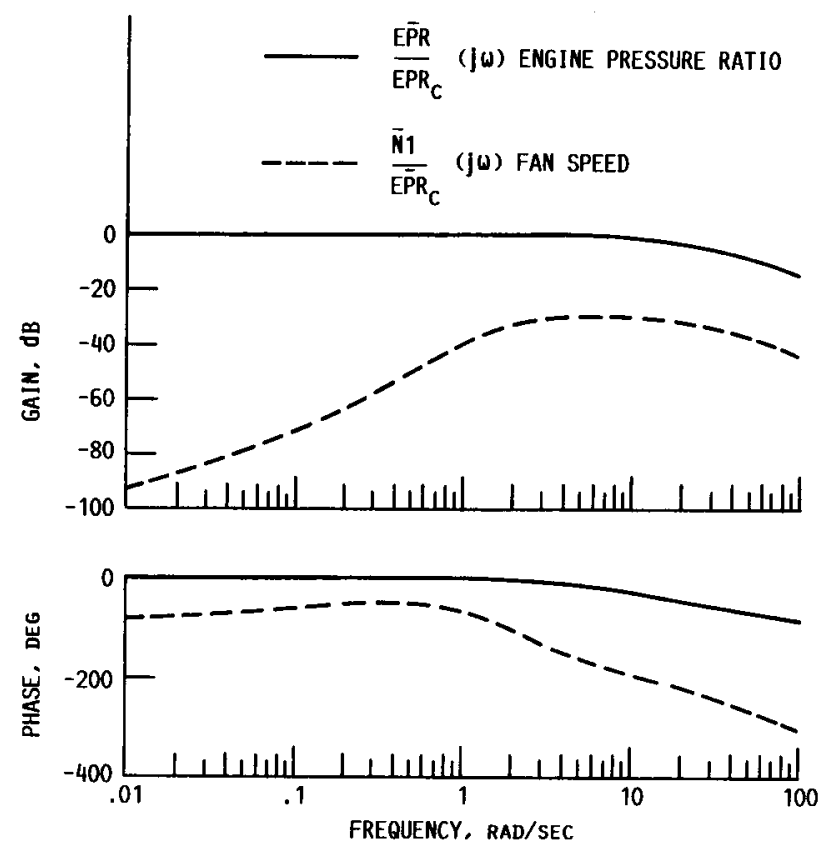

FIGURE 6B. - CLOSED-LOOP SYSTEM FREQUENCY RESPONSE TO EPR COMMANDS (SCALED).

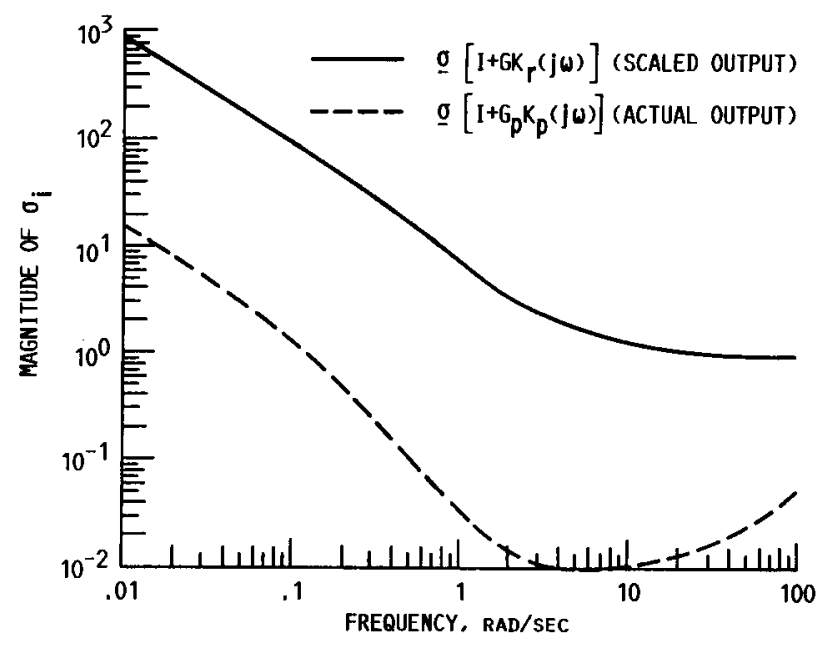

FIGURE 7. - MINIMUM RETURN DIFFERENCE SINGULAR VALUES AT SCALED PLANT OUTPUT AND ACTUAL PLANT OUTPUT (WITH REDUCED ORDER COMPENSATOR).

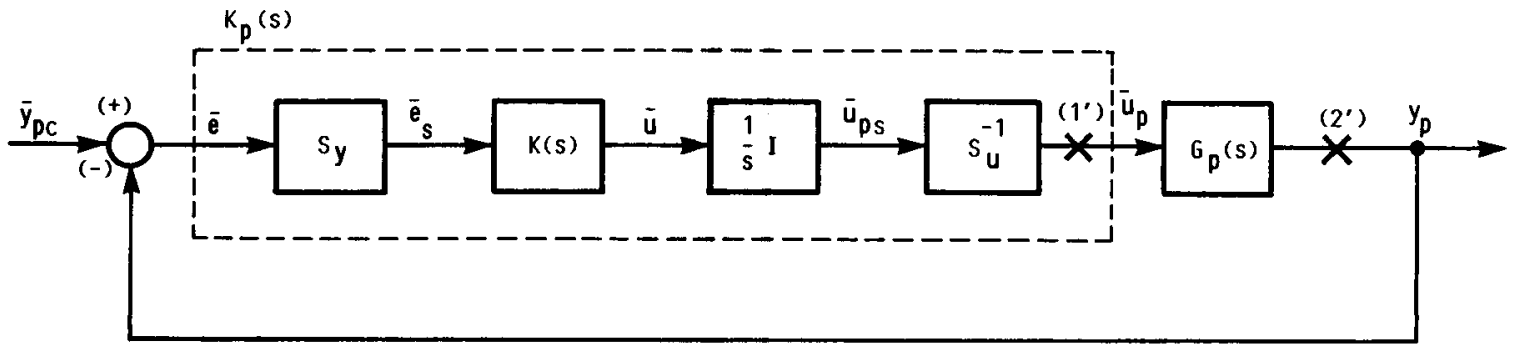

FIGURE 8. - BLOCK DIAGRAM FOR COMPENSATOR IMPLEMENTATION. 


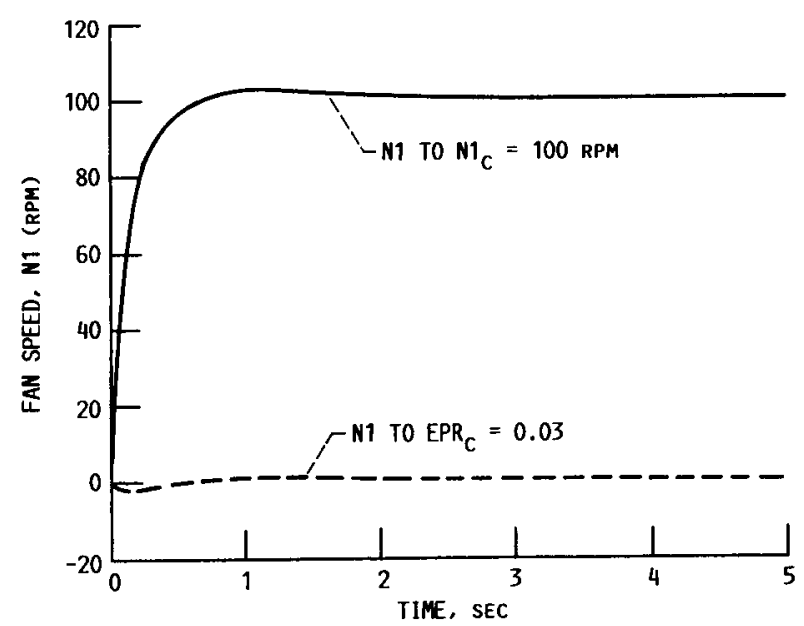

FIGURE 9. - CLOSED-LOOP SYSTEM RESPONSE, FAN SPEED (N1) TO STEP COMMANDS.

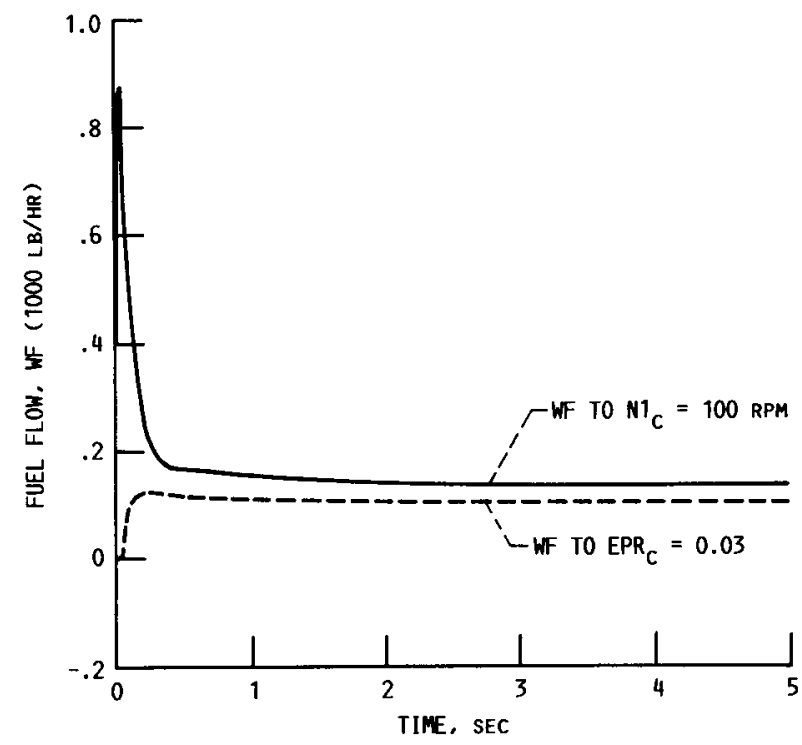

FIGURE 11. - CLOSED-LOOP CONTROL VARIATIONS, FUEL FLOW (WF) TO STEP COMHANDS.

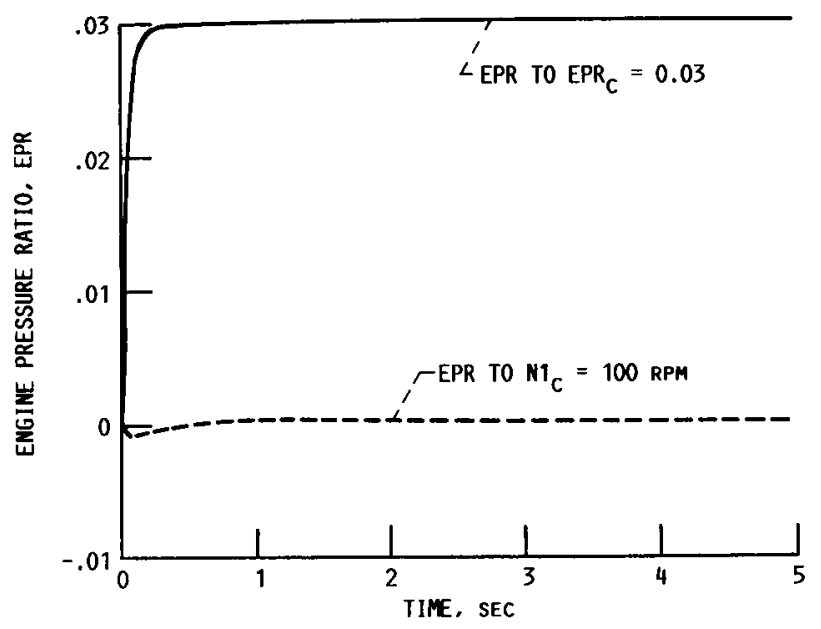

FIGURE 10. - CLOSED-LOOP SYSTEM RESPONSE, EPR TO STEP COMMANDS.

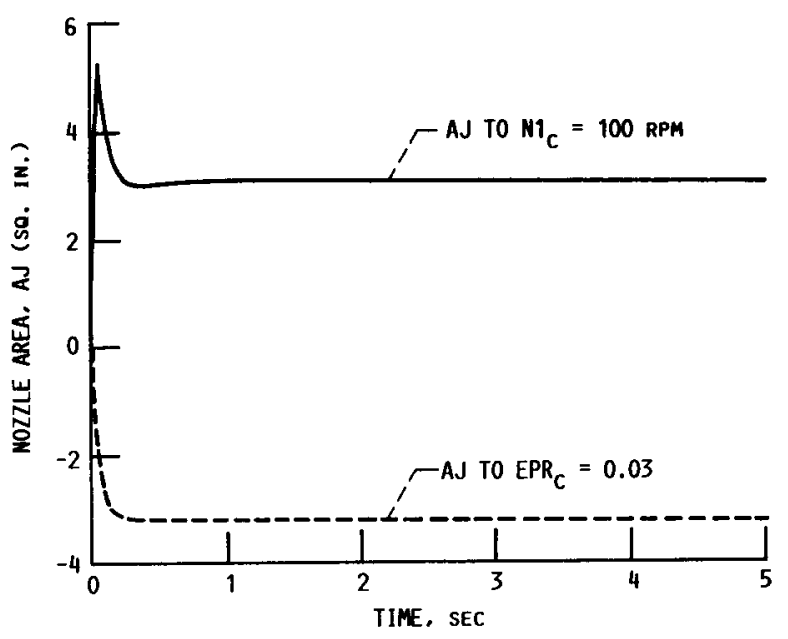

FIGURE 12. - CLOSED-LOOP CONTROL VARIATIONS, NOZZLE AREA (AJ) TO STEP COMMANDS. 


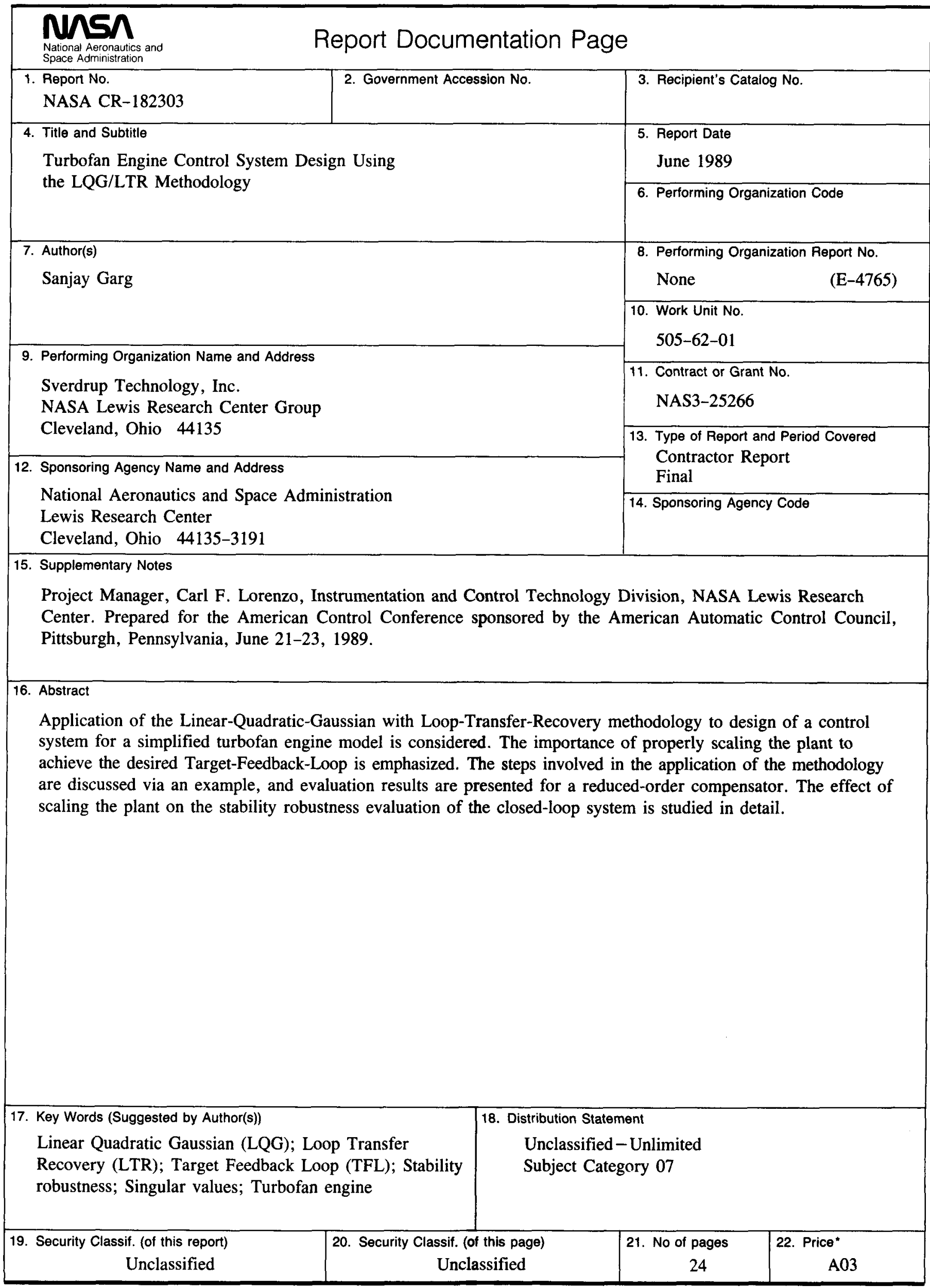

